\title{
Mucopyocele of Concha Bullosa: A Rare Presentation as Orbital Swelling
}

\author{
${ }^{1}$ Hitendra P Singh, ${ }^{2}$ Sunil Kumar, ${ }^{3}$ Anupriya Hajela, ${ }^{4}$ Satya P Agarwal
}

\begin{abstract}
Whenever there is pneumatization of either turbinate, it is known as concha bullosa (CB). In the case of middle turbinate, it is the most common anatomical aberration. A mucopyocele of $\mathrm{CB}$ is very rarely seen. A 13-year-old male presented with the complaints of gradually progressive swelling on medial aspect of right eye with nasal obstruction, nasal discharge, and facial heaviness for 3 years. Computed tomography (CT) scan of the paranasal sinuses showed a well-defined cystic lesion of thick fluid attenuation with thin shell in the periphery located at the medial canthus of right eye involving the lacrimal sac region with stranding of adjacent periorbital fat plane. Lesion is seen causing erosion of lamina papyracea. After complete hematological and preanesthetic assessment, surgery was planned for the patient under general anesthesia. The lateral lamella and inferior part of $\mathrm{CB}$ was excised to drain out the pus and prevent recurrences. Patient remained symptom free in the follow-up period.
\end{abstract}

Keywords: Concha bullosa, Endoscopic sinus surgery, Mucopyocele.

How to cite this article: Singh HP, Kumar S, Hajela A, Agarwal SP. Mucopyocele of Concha Bullosa: A Rare Presentation as Orbital Swelling. Int J Otorhinolaryngol Clin 2016;8(2):53-55.

Source of support: Nil

Conflict of interest: None

\section{INTRODUCTION}

Concha bullosa (CB) is one of the most common anatomical variations of the middle turbinate. It is described as aeration of horizontal part of middle turbinate with or without involvement of the vertical part. However, mucoceles of CB have been rarely reported. When a mucocele becomes infected, it is referred to as pyocele. ${ }^{1}$ In most of the cases mucoceles are situated in the frontoethmoidal complex of paranasal sinuses. ${ }^{2,3}$ A mucopyocele of CB is a very rare clinical entity.

\section{CASE REPORT}

A 13-year-old male presented with the complaints of gradually progressive swelling on medial aspect of right

\footnotetext{
${ }^{1,2}$ Associate Professor, ${ }^{3}$ Junior Resident, ${ }^{4}$ Professor and Head

${ }^{1-4}$ Department of ENT and Head Neck Surgery, King George's Medical University, Lucknow, Uttar Pradesh, India
}

Corresponding Author: Hitendra P Singh, Associate Professor Department of ENT and Head Neck Surgery, King George's Medical University, Lucknow, Uttar Pradesh, India, Phone: +919456048923, e-mail: drhpsingh77@gmail.com eye with nasal obstruction, nasal discharge, and facial heaviness for 3 years (Fig. 1). Patient was having no history of bleeding from nasal cavity, loss of smell, and watering from eye. There were no other ocular symptoms. Patient had received conservative treatment in the form of nasal decongestants and nasal steroids with only partial improvement in the symptoms. His past history was unremarkable.

Anterior rhinoscopic examination revealed an enlarged middle turbinate on right side with mild deviated nasal septum toward left side. On endoscopic examination, a massive middle turbinate with normal overlying mucosa was seen causing mild displacement of nasal septum toward left side (Fig. 2). His ophthalmologic examination showed mild lateral displacement of right eye with no evidence of exophthalmos. Ocular motion and visual acuity were normal. Computed tomography (CT) scan of the paranasal sinuses was ordered which showed a well-defined cystic lesion of thick fluid attenuation with thin shell in periphery located at the medial canthus of right eye involving the lacrimal sac region with stranding of adjacent periorbital fat plane. Lesion was seen causing erosion of lamina papyracea. There was associated mucosal hypertrophy in right maxillary sinus and bilateral ethmoid sinuses suggestive of sinusitis (Figs 3 and 4).

After complete hematological and preanesthetic assessment, surgery was planned for the patient under

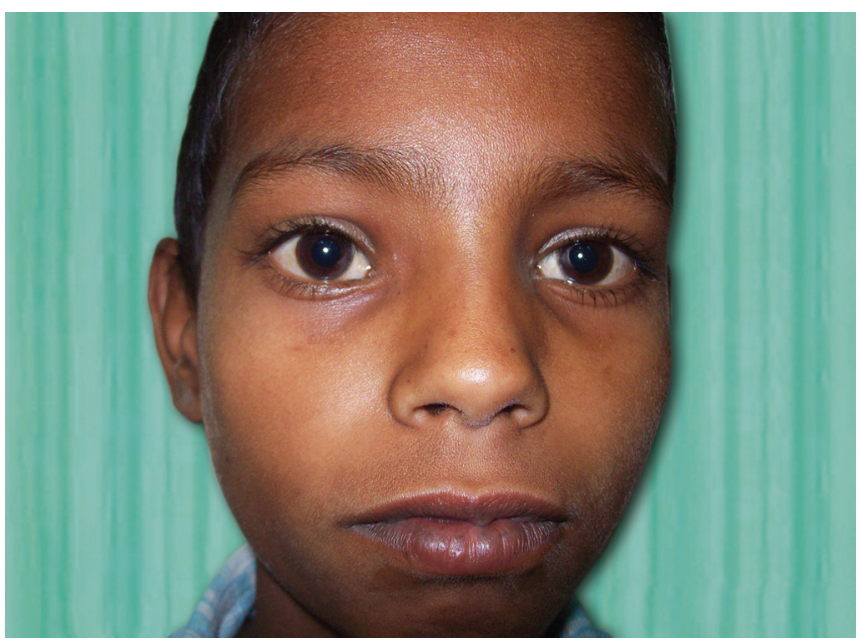

Fig. 1: The patient showing bulge over medial canthus of right eye 


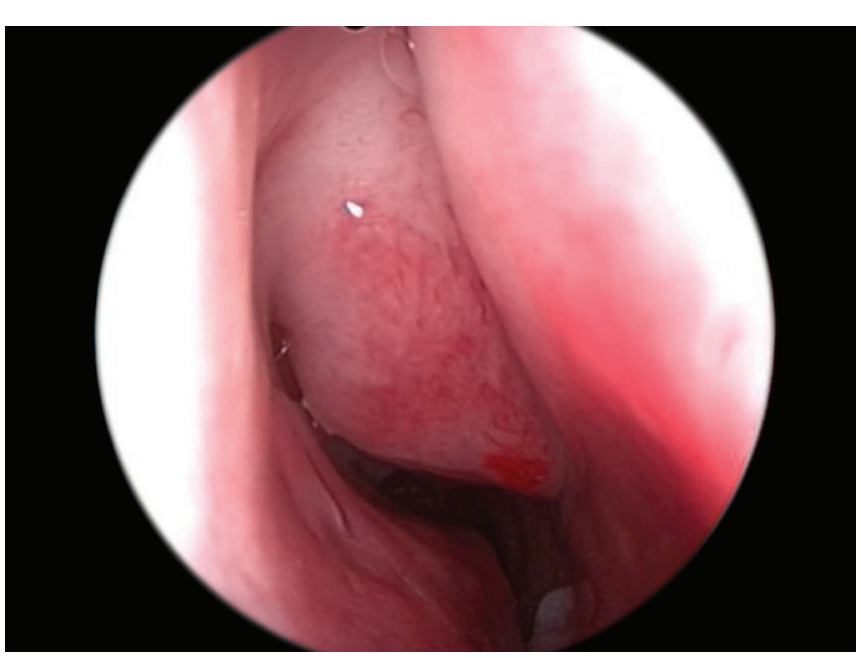

Fig. 2: Endoscopic photograph showing huge $C B$

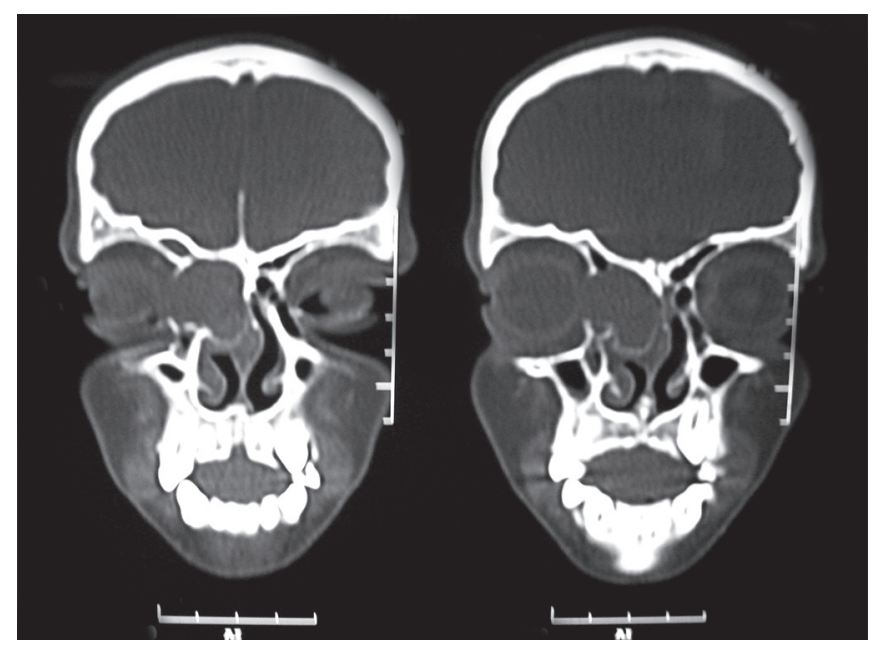

Fig. 4: Coronal CT scan of the patient showing well-defined cystic lesion of thick fluid attenuation with thin shell in periphery located at the medial canthus of right eye involving the lacrimal sac region with stranding of adjacent periorbital fat

general anesthesia. As soon as the mass was punctured with a needle, pus gushed under pressure to reveal a huge shell of very thin bone. The lateral lamella and inferior part of $\mathrm{CB}$ was excised to drain out the pus and prevent recurrences. Excessive manipulation of medial lamella of $\mathrm{CB}$ was avoided to prevent the instability of middle turbinate and complications. Patient was given routine post-functional endoscopic sinus surgery care and oral antibiotics for 1 week. He was advised to continue saline nasal douches for at least 2 months. His symptoms of nasal obstruction, nasal discharge, and facial heaviness gradually disappeared; however, bulge over medial aspect of eye remained.

\section{REVIEW OF LITERATURE AND DISCUSSION}

$A C B$ is a pneumatized turbinate irrespective of the degree and location of aeration. It is the most common anatomical variation of paranasal sinuses. Majority of

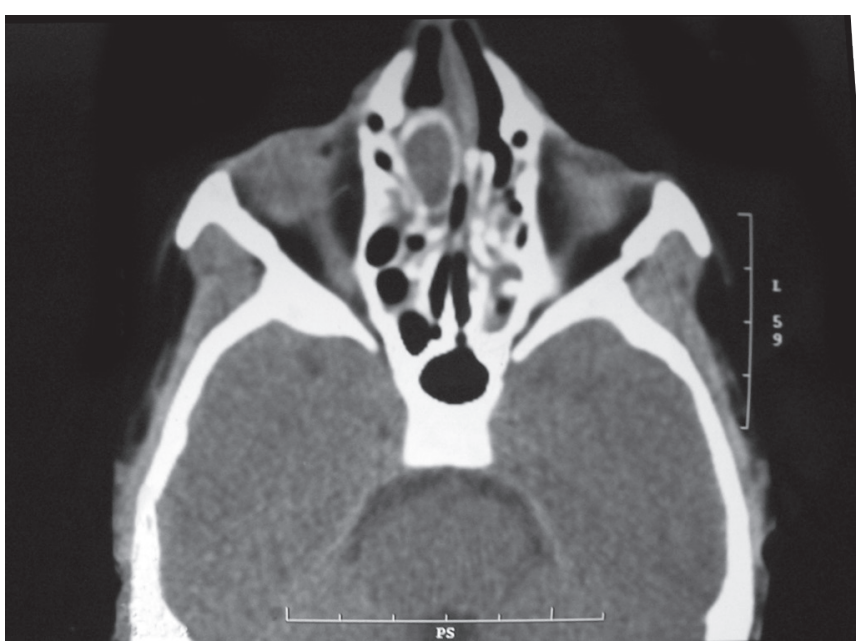

Fig. 3: Axial CT scan of the patient showing well-defined cystic lesion of thick fluid attenuation involving the anterior part of middle turbinate

$\mathrm{CB}$ occurs in the middle turbinate and can be unilateral or bilateral. The incidence of $\mathrm{CB}$ varies from 14 to $53 \%{ }^{4}$ According to the location of pneumatization, $\mathrm{CB}$ has been classified as lamellar when the vertical lamella is involved, bulbous when the inferior bulbous segment is involved, and extensive when the entire concha is involved. ${ }^{5}$

The mucosal lining of $\mathrm{CB}$ is a mucociliary system like the mucous membrane of the rest of the sinuses. It drains the $\mathrm{CB}$ cell lumen into frontal recess. ${ }^{6}$ Factors like trauma, polyps, surgery, or tumor can cause obstruction of ostium and lead to mucocele and when infected, it is called a mucopyocele. After mucocele or mucopyocele formation, CB may expand to occupy the adjacent structure and is capable of local bone destruction. Therefore, a patient with $\mathrm{CB}$ mucocele may present with headache, orbital pain, exophthalmos, nasal discharge, postnasal drip, nasal obstruction, and anosmia as possible symptoms. ${ }^{4}$ In our case, the patient presented with complaints of swelling over medial aspect of right eye simulating a frontoethmoidal mucocele due to extension of CB mucopyocele into orbital space. Patient also presented with on and off nasal blockage, nasal discharge and facial heaviness secondary to obstruction of osteomeatal complex by CB mucopyocele.

The diagnosis is usually suspected from its typical radiological finding. In our case, CT scan of the paranasal sinuses revealed a well-defined cystic lesion of thick fluid attenuation in the medial aspect of right eye involving lacrimal sac region and erosion of lamina papyracea. Findings were suggestive of frontoethmoidal mucocele. It was the endoscopic finding that helped us to determine the diagnosis of mucopyocele of $\mathrm{CB}$.

The treatment modality for $\mathrm{CB}$ mucocele is endoscopic sinus surgery. Four methods have been mentioned to manage mucocele surgically. Lateral marsupialization, 
medial marsupialization, crushing, and transverse excision. ${ }^{7}$ The method of choice for surgical access depends on localization of mucocele. In the present case, the lateral lamella and inferior half of $\mathrm{CB}$ was excised to drain the pus and prevent recurrences. We avoided excessive manipulation of medial lamella as it attaches to the skull base and can cause instability of middle turbinate.

\section{REFERENCES}

1. Abdel-Aziz M. Mucopyocele of the concha bullosa presenting as a large nasal mass. J Craniofac Surg 2011 May;22(3):1141-1142.

2. Dhepnorrarat RC, Subramaniam S, Sethi DS. Endoscopic surgery for frontoethmoidal mucoceles: a 15 year experience. Otolaryngol Head Neck Surg 2012 Aug;147(2):345-350.
3. Toledano A, Herráiz C, Mate A, Plaza G, Aparicio JM, De Los Santos G, Galindo AN. Mucocele of the middle turbinate: a case report. Otolaryngol Head Neck Surg 2002 Apr;126(4): 442-444.

4. Okuyucu S, Akoğlu E, Dağli AS. Concha bullosa pyocele. Eur Arch Otorhinolaryngol 2008 Mar;265(3):373-375.

5. Bolger WE, Butzin CA, Parsons DS. Paranasal sinus bony anatomic variations and mucosal abnormalities: $\mathrm{CT}$ analysis for endoscopic sinus surgery. Laryngoscope 1991 Jan;101 (1 Pt 1):56-64.

6. Zinreich SJ, Mattox DE, Kennedy DW, Chisholm HL, Diffley DM, Rosenbaum AE. Concha bullosa: CT evaluation. J Comput Assist Tomogr 1998 Sep-Oct;12(5):778-784.

7. Marianowski R, Farragi M, Zerah M, Brunelle F, Manach Y. Subdural empyema complicating a concha bullosa pyocele. Int J Pediatr Otorhinolaryngol 2002 Sep 24;65(3):249-252. 